\title{
Motivating factors affecting the individual energy consumption behavior
}

\author{
Jalal ud Din Akbar ${ }^{1}$, and Muhammad Ridhuan Tony Lim Abdullah ${ }^{1}$ \\ ${ }^{1}$ Department of Management and Humanities Universiti Teknologi Petronas, 32610 Seri Iskandar, Perak \\ ${ }^{1}$ Department of Management and Humanities Universiti Teknologi Petronas, 32610 Seri Iskandar, Perak
}

\begin{abstract}
Global challenges of climate change and environmental deterioration helped in formulating seventeen sustainable development goals through United Nation. Achieving these sustainable goals, Malaysia initiated and track progress towards affordable and clean energy. The natural environment and climate are mostly influenced by human behavior. Due to the role of human behavior in climate change, a strong tendency towards the pursuit of energy sustainability exists. Attention is paid to strengthen the human behavior from general acts of doing things to carrying specific actions by adopting a responsible behavior into daily routine. A number of factors were identified through literature such as social structure, institution, and education for understanding the individual behavior for sustainability with regard to energy consumption. Many experts related to the field of energy were engaged to sort and prioritize these factors with respect to their importance by using multi-criteria decision making tool of analytical hierarchy process (AHP). The experts were selected from different sectors such as academia, NGOs and industry. With the help of experts, a framework of individual energy consumption behaviour is developed to allow the government and other stakeholders to make policies accordingly to achieve energy sustainable.
\end{abstract}

\section{INTRODUCTION}

Our modern social lifestyles are greatly reliant on energy. It is inevitable that the intensive energy consumption is continuing to increase if we remain with the current lifestyle. Focusing merely on efficient technology for production, delivery, and consumption to achieve energy sustainability is insufficient (Piccolo, De Liddo, Burel, Fernandez, \& Alani, 2018). Similarly, the effort to use a mix of fossil and renewable energy sources are taken into consideration, but the rate of increase in renewable energy production is not encouraging. The pursuit of energy sustainability will only succeed if society demands less energy. Hence, the right values towards the environment and sustainable energy consumption behavior are equally pertinent. And change in individual energy consumption behavior could mitigate environmental degradation problems (Parag, 2020).

Previous studies shows individual energy consumption behavior has a high impact on energy demand (Nahiduzzaman et al., 2018). According to to Williams, Thondhlana, and Kua (2020), roughly $20 \%$ of total electricity consumption can be saved with change in individual behavior. In an another study, it was revealed that minor changes in individual energy consumption behaviors can yield between 10 to 20 percent of energy savings (Burger et al., 2015). It means that user behavior is a key to explain energy consumption and contribution towards environmental pollution (N'Famory, Xu, \& Binyet, 2018). Hence, it can be concluded that studying behavioral factors of social structure, institution and education could save the environmental degradation and climate change. The current study will be carried out to prioritize the relevant behavioral factors of individual energy consumption through Analytical Hierarchy Process (AHP) decision-making in the Malaysian context. The objective of the study is to develop a framework with identified relevant factors and prioritize them based on stakeholder's view. The conceptual model of individual energy consumption behavior proposed and adopted by the current study fall under decision support model. 


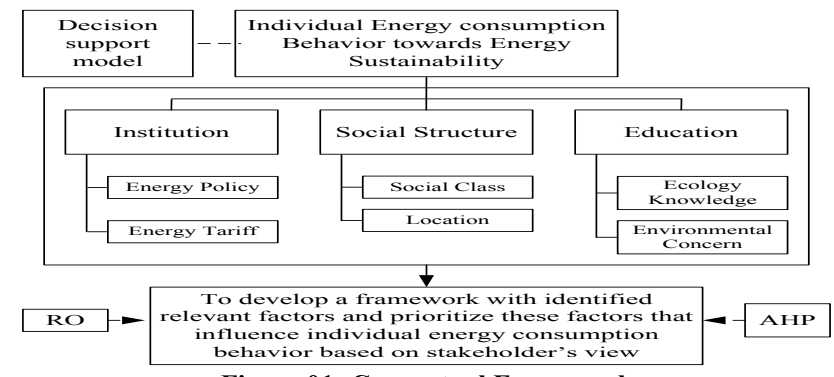

Figure 01: Conceptual Framework

\section{LITERATURE}

Issues such as climate change, geo-strategies, economics, technologies and sustainable development goals have induced changes in the energy systems of many countries (Delina \& Janetos, 2018). Some countries adopted energy transition strategies for fundamental reconfigurations of the respective energy systems. These transformations ranges from techno-economic infrastructures on the supply side to changes of energy consumption patterns on the demand side (C. Chen, Xue, Cai, Thomas, \& Stückrad, 2019; Rogge, Pfluger, \& Geels, 2020).

Many existing energy transition strategies concentrate on technological solutions, while efforts about behavior change are being absent or even downplayed (Tozer \& Klenk, 2018). There are indications that individual energy consumption behavior play an important role in energy transition (Bornemann, Sohre, \& Burger, 2018). Household consumption contributes to $72 \%$ of global greenhouse gas emissions (Dubois et al., 2019). Researchers are focusing individuals to change their behavior through climate policymaking (Dubois, 2015; Dubois et al., 2019). Furthermore, current generation has to change their behavior for next generation wellbeing through behavioral mitigation wedge.(Langaas, Fløttum, \& Gjerstad, 2019). The reduce emissions through behavioral change can surpass the low carbon infrastructural supply or the political pledges under the Paris Accord (BowsLarkin, 2015).

In Malaysia, energy consumption was around 14.5 Million tons of oil equivalent (Mtoe) in 1990, 45.6 Mtoe in 2007 (Outlook, 2011) and estimated at 116 Mtoe in 2020 (Ali, Razman, \& Awang, 2020; Moey et al., 2020; Shahmohammadi, 2015). CO2 emission was recorded at around 43.7 million tons of Carbon Equivalent (Mt-c) in 2007 and expected approximately to $86 \mathrm{Mt}-\mathrm{c}$ in the year 2030 (Outlook, 2011). The importance of economic growth through energy consumption could not be undermined (Good, 2019; Shahzad, Doğan, Sinha, \& Fareed, 2020; Sorrell, 2015), and achieving the growing demand for energy in a sustainable style is crucial for the country's competitive edge in the twenty first century (Kardooni, Yusoff, \& Kari, 2015; Moey et al., 2020).

Individual behavioral patterns, influenced by a diversity of contextual factors such as social structures, educational and so on, are equally important with regards to institutional systems and infrastructures (Bögel, Upham, Shahrokni, \& Kordas, 2020; Boudet, 2019; Prokopy et al., 2019). Considering this, sustainable energy consumption behaviour incorporates a variety of actions as well as needs for change. The subsections below, present a discussion on the review of the constructs (with their respective dimensions) of social structure, institutions and education.

\subsubsection{Social Structure}

This construct involves the distinctive arrangements of social systems by means of socioeconomic stratification or other closely related patterns in a society. The construct of social structure is treated under the dimensions of class and location.

\subsubsection{Social Class}

According to Goldstein, Cialdini, and Griskevicius (2008), individuals are inclined to interact, as well as behave in ways that are in line with other that share similar contexts, and norms. As a result, Pillay (2013) on energy use revealed that South Africa's middle-income and upper income class are responsible for highest amount of electrical energy consumption. This finding is in congruence with the assertion of Goldstein et al. (2008), who argue that individuals within the same social strata tend to accommodate similar behavioral norms.

\subsubsection{Location}

Residential location suggested by some research scholars as being pertinent to the consumption patterns of individuals. According to Hernandez, Lister, and Suarez (2011), housing location significantly influences energy consumption behaviour in households. Residents in multifamily as well as single family residential units with 
higher density populations consume less electricity per unit compared to low-density neighborhoods. Individuals with easy accessibility to bus or train station have a significant negative influence on household energy consumption. It implies that construction of homes in close proximity to bus or train stations could decrease the aggregate energy demand of the population (Biying, Zhang, \& Fujiwara, 2012).

\subsubsection{Institution}

This construct involves the structures and/or mechanisms of social order, governing the behaviour of individuals within a given society. The construct of institution is treated under the dimensions of energy policy and energy tariff.

\subsubsection{Energy Policy}

Energy policy involves the way governmental authorities address matters pertaining to energy development such as energy production, energy distribution and energy consumption (Frederiks, Stenner, \& Hobman, 2015). According to Shove (2010), individuals are active participants in the production consumption cycles. In a quantitative survey, Fielding, Louis, Warren, and Thompson (2010) observed that an all-inclusive understanding of households' behavioral and environmental attitudes is needed to enact energy consumption policies for a significant positive change.

\subsubsection{Energy Tariff}

Energy tariffs are pricing structures charged for energy consumption. According to Stern (1992), rebates are important for promoting energy conservation. He states that rebates in form of tax incentives provide energy consumers as well as companies with all-encompassing incentives, as well as opportunities to modify their energy consumption behaviour. In line with this assertion, Pillay (2013) argues that individual energy consumers can modify their behaviour to suit their consumption preferences, but the significant changes required in energy use are bounded by the upstream regulatory institutions.

\subsubsection{Education}

This construct involves the awareness as well as information acquired in line with knowledge, values, beliefs, and habit. The construct of education is treated under the dimensions of ecology knowledge, and environmental concern.

\subsubsection{Ecology Knowledge}

This deals with the theoretical and practical understanding of humans and their physical surroundings towards environmental protection efforts. The findings of Henryson, Håkansson, and Pyrko (2000) shows household energy consumers confusion over the optimum energy use required for environmental conservation efforts. Research by Pillay (2013) revealed South African households enough knowledge on energy efficiency and its effect on ecology. Research scholars such as Gardner and Stern (2002) and Abrahamse, Steg, Vlek, and Rothengatter (2005) suggested the provision of accurate information about energy problems and energy conservation for an increase in knowledge. However, Abrahamse et al. (2005) argues that this information is more likely to inspire sustainable energy consumption behavior when it aligns with people's central values.

\subsubsection{Environmental Concern}

For energy consumption and environmental sustainability, Kaiser and Weber (1999) noted that provision of knowledge, information and inspiration is essential in shaping attitudes, values as well as norms in line with environmental concern. However, as reported by Martiskainen (2007), an all-inclusive and comprehensive approach is needed of not only focusing on energy consumption at home, but also taking into consideration, transportation, waste as well as water usage, all of which in due course have energy and subsequently climate impact.

\subsection{METHODOLOGY}

This study proposes multiple criteria decision-making for identifying potential factors effecting individual energy consumption behavior. It enables assessment by multiple stakeholders or expert judgments and employed to cope with the imprecision and vagueness of information in the individual energy consumption behavior evaluation process. The analytical hierarchy process (AHP), since its discovery is one of the most frequently used critical decision-making tools. Many high-quality studies have been published based on AHP (C.-T. Chen, Lin, \& Huang, 2006; Kannan, de Sousa Jabbour, \& Jabbour, 2014).

AHP is employed to provide a simple approach to help decision-makers to prioritize among the relevant factors. Using AHP ensures that qualitative judgment is quantified to provide precise comparisons and to minimize 
or to eliminate any unbalanced scale of judgments, imprecision, and uncertainty among pair-wise comparisons (Borade, Kannan, \& Bansod, 2013). Based on the problem description, the methodology of AHP is described in the following sections.

\subsubsection{Analytical Hierarchy Process (AHP)}

Analytical Hierarchy Process (AHP) is the multiple criteria decision-making tool dealing with the formulation of multi-criteria decision-making problems (Jiang, Zhang, \& Sutherland, 2011). The various steps of AHP are described as follows:

Step 1: Define Problem statement: First, the problem statement should be defined clearly, as it drives the whole process. Before the use of AHP, it should clearly explain what their problems are and why AHP has to be used. In the absence of weighting instrument, measuring the relative weights of the sources is acceptable (Saaty, 1994).

Step 2: Identify the potential factors and sub factors and questionnaire development: Next is to identify the potential factors and sub-factors related to the individual energy consumption behavior through detailed literature review. A set of questionnaires is developed for each factor and sub factor of the study. Experts are involved to go through numerous factors and sub-factors. They have the authority to drop or add certain factors and subfactors and rearrange their hierarches and levels to clearly give some direction to the study.

Step 3: Evaluation of the Factors and sub-factors by Stakeholders or expert: The factors and sub-factors of individual energy consumption behavior are evaluated through a questionnaire. Purposive sampling (Skulmoski, Hartman, \& Krahn, 2007) is used in the current study. A purposive sample is necessary where people are selected not to represent the general population, rather their expert ability to answer the research questions (Fink \& Kosecoff, 1985; Skulmoski et al., 2007). The sample size suggested by some studies is 10-15 respondents based on the degree of homogeneity of respondents (Adler \& Ziglio, 1996). Some scholars recommend 10 to 50 respondents (Jones \& Twiss, 1978).

Step 4: Identification of relevant factors and sub factors for individual energy consumption behavior: In this step the factors and sub factors of individual energy consumption behaviour are identified through comparing the weight of each factor and sub-factors with the threshold value ' $\tilde{a}^{\prime}$. The identified factors and sub-factors of individual energy consumption behavior and their hierarchy levels are shown in table 1

Table 1: Factors and Sub-Factors of Individual Energy Consumption Behavior

\begin{tabular}{|l|l|l|}
\hline Goal & Factor & Sub Factors \\
\hline \multirow{4}{*}{$\begin{array}{l}\text { Individual energy consumption } \\
\text { behavior }\end{array}$} & \multirow{2}{*}{ Social Structure } & Class \\
\cline { 2 - 3 } & \multirow{2}{*}{ Institution } & Location \\
\cline { 2 - 3 } & \multirow{2}{*}{ Education } & Energy Policy \\
\cline { 2 - 3 } & & Energy Tariff \\
\cline { 2 - 3 } & & Ecology Knowledge \\
\hline
\end{tabular}

Step 5: Development of a second questionnaires with relevant factors of Individual energy consumption Behavior and evaluation through AHP: The second set of questionnaire is used to collect the data from experts. The scale used for measuring the questionnaires is based on a Saaty scale (see Table 2). The experts of individual energy consumption behavior are from the industry, non-government organizations and academic institutions.

Table 2: Scoring Scale for Factor Comparison

\begin{tabular}{|l|l|l|}
\hline 1 & Equal importance & The specified criteria contribute equally to objective \\
\hline 3 & Weakly Importance & A criterion is slightly favored compared with other \\
\hline 5 & Essentially Importance & A criterion is clearly dominates the other in importance \\
\hline 7 & Very Strongly Importance & A criterion is strongly favored compared with other \\
\hline 9 & Absolutely Importance & A criterion is unquestionably more important than other \\
\hline $2,4,6,8$ & Intermediate Values & When compromise is giving between two adjacent judgments \\
\hline
\end{tabular}

Step 6: Pair wise comparisons of the relevant factors using Analytical Hierarchy Process tool: The data is collected for making a pairwise comparison. Expert choice version 11 is used for pairwise comparison. AHP helps in defining study goals, identify factors and sub-factors of individual energy consumption behaviour.

Step 7: Essential factors prioritize in descending order of importance: Next step is to synthesize the solutions for the derivation of the individual energy consumption behaviour measures. The normalized weights of the factors 
and sub-factors obtained from the previous step are added together with respect to all succeeding hierarchical levels to attain the global composite priority weights of all sub-factors used in the AHP framework.

Step 8. Formulation of Framework: In this step, the individual energy consumption behaviour index or framework is formulated. The factors and sub-factors of individual energy consumption are listed in descending order of importance.

\subsection{CONCLUSION}

The consumers are unable to make decision by themselves and often fails to align their knowledge, values, attitudes and lifestyle with efficient energy consumption. A growing body of research indicates that consumer choices and behaviour are often driven by cognitive biases and inconsistent tendencies. Yet practitioners and policymakers seeking to promote energy efficiency and conservation often overlook these cognitive biases and factors. To ensure cost-effectiveness, it is important to consider these factors, when developing strategies for encouraging sustainable energy use, and for motivating environmental behaviour more broadly. By understanding the individual consumption behaviour and prioritization of the relevant factors through analytical hierarchy process, policymakers will be in better position to design intervention strategies through energy policy and energy tariff in Malaysia.

\section{Acknowledgement}

The research study was part of an FRGS (Fundamental Research Grant Scheme) project. The project is supported under the COST CENTER: 015MA0-024. The authors would like to express their appreciation to the support given by the FRGS of The Ministry of Higher Education, Malaysia.

\section{REFERENCE}

Abrahamse, W., Steg, L., Vlek, C., \& Rothengatter, T. (2005). A review of intervention studies aimed at household energy conservation. Journal of environmental psychology, 25(3), 273-291.

Adler, M., \& Ziglio, E. (1996). Gazing into the oracle: The Delphi method and its application to social policy and public health: Jessica Kingsley Publishers.

Ali, S. S. S., Razman, M. R., \& Awang, A. (2020). The nexus of population, GDP growth, electricity generation, electricity consumption and carbon emissions output in Malaysia. International Journal of Energy Economics and Policy, 10(3), 84.

Biying, Y., Zhang, J., \& Fujiwara, A. (2012). Analysis of the residential location choice and household energy consumption behavior by incorporating multiple self-selection effects. Energy Policy, 46, 319-334.

Bögel, P. M., Upham, P., Shahrokni, H., \& Kordas, O. (2020). What is needed for citizen-centered urban energy transitions: Insights on attitudes towards decentralized energy storage. Energy Policy, 112032.

Borade, A. B., Kannan, G., \& Bansod, S. V. (2013). Analytical hierarchy process-based framework for VMI adoption. International Journal of Production Research, 51(4), 963-978.

Bornemann, B., Sohre, A., \& Burger, P. (2018). Future governance of individual energy consumption behavior change-A framework for reflexive designs. Energy research \& social science, 35, 140-151.

Boudet, H. S. (2019). Public perceptions of and responses to new energy technologies. nature energy, $4(6), 446-455$.

Bows-Larkin, A. (2015). All adrift: aviation, shipping, and climate change policy. Climate Policy, 15(6), 681-702.

Burger, P., Bezençon, V., Bornemann, B., Brosch, T., Carabias-Hütter, V., Farsi, M., . . . Samuel, R. (2015). Advances in understanding energy consumption behavior and the governance of its change-outline of an integrated framework. Frontiers in energy research, 3, 29.

Chen, C.-T., Lin, C.-T., \& Huang, S.-F. (2006). A fuzzy approach for supplier evaluation and selection in supply chain management. International journal of production economics, 102(2), 289-301.

Chen, C., Xue, B., Cai, G., Thomas, H., \& Stückrad, S. (2019). Comparing the energy transitions in Germany and China: Synergies and recommendations. Energy Reports, 5, 1249-1260. 
Delina, L., \& Janetos, A. (2018). Cosmopolitan, dynamic, and contested energy futures: navigating the pluralities and polarities in the energy systems of tomorrow. Energy research \& social science, 35, 1-10.

Dubois, G. (2015). Living on a carbon diet. Low Carbon Economy, 6(01), 13.

Dubois, G., Sovacool, B., Aall, C., Nilsson, M., Barbier, C., Herrmann, A., . . . Nadaud, F. (2019). It starts at home? Climate policies targeting household consumption and behavioral decisions are key to low-carbon futures. Energy research \& social science, 52, 144-158.

Fielding, K. S., Louis, W. R., Warren, C. M., \& Thompson, A. (2010). Environmental sustainability in residential housing: understanding attitudes and behaviour towards waste, water, and energy consumption and conservation among Australian households. AHURI Final Report, 152, 1-132.

Fink, A., \& Kosecoff, J. (1985). How to conduct surveys. Beverly Hills: CA: Sage Publications.

Frederiks, E. R., Stenner, K., \& Hobman, E. V. (2015). Household energy use: Applying behavioural economics to understand consumer decision-making and behaviour. Renewable and Sustainable Energy Reviews, 41, 1385-1394.

Gardner, G., \& Stern, P. (2002). Human reactions to environmental hazards: Perceptual and cognitive processes. Environmental problems and human behavior, 205-252.

Goldstein, N. J., Cialdini, R. B., \& Griskevicius, V. (2008). A room with a viewpoint: Using social norms to motivate environmental conservation in hotels. Journal of consumer Research, 35(3), 472482.

Good, N. (2019). Using behavioural economic theory in modelling of demand response. Applied Energy, 239, 107-116.

Henryson, J., Håkansson, T., \& Pyrko, J. (2000). Energy efficiency in buildings through informationSwedish perspective. Energy Policy, 28(3), 169-180.

Hernandez, D., Lister, M., \& Suarez, C. (2011). Location efficiency and housing type: Boiling it down to BTUs: Jonathan Rose Companies.

Jiang, Z., Zhang, H., \& Sutherland, J. W. (2011). Development of multi-criteria decision making model for remanufacturing technology portfolio selection. Journal of Cleaner Production, 19(17-18), 1939-1945.

Jones, H., \& Twiss, B. C. (1978). Forecasting technology for planning decisions.

Kaiser, F. G., \& Weber, O. (1999). Umwelteinstellung und ökologisches Verhalten: Wie groß ist der Einfluß wirklich? GAIA-Ecological Perspectives for Science and Society, 8(3), 197-201.

Kannan, D., de Sousa Jabbour, A. B. L., \& Jabbour, C. J. C. (2014). Selecting green suppliers based on GSCM practices: Using fuzzy TOPSIS applied to a Brazilian electronics company. European Journal of Operational Research, 233(2), 432-447.

Kardooni, R., Yusoff, S. B., \& Kari, F. B. (2015). Barriers to renewable energy development: five fuel policy in Malaysia. Energy \& Environment, 26(8), 1353-1361.

Langaas, R. F., Fløttum, K., \& Gjerstad, $\varnothing$. (2019). Expressing one's conceptions of lifestyle in a climate perspective. Cahiers de praxématique(73).

Martiskainen, M. (2007). Affecting consumer behaviour on energy demand.

Moey, L. K., GOH, K. S., Tong, D. L., Chong, P. L., Adam, N. M., \& Ahmad, K. A. (2020). A review on current energy usage and potential of sustainable energy in Southeast Asia countries. Journal of Sustainability Science and Management, 15(2), 89-107.

N'Famory, C., Xu, D., \& Binyet, E. (2018). Enhancing household energy consumption: How should it be done? Renewable and Sustainable Energy Reviews, 81(P1), 669-681.

Nahiduzzaman, K. M., Aldosary, A. S., Abdallah, A. S., Asif, M., Kua, H. W., \& Alqadhib, A. M. (2018). Households energy conservation in Saudi Arabia: Lessons learnt from change-agents driven interventions program. Journal of Cleaner Production, 185, 998-1014.

Outlook, A. E. (2011). The 3rd ASEAN Energy Outlook. Asean SOE Leaders, Ministry of the Economy, trade and industry, Japan: The Institute of Energy Economics, The Asean Centre for Energy, The National ESSPA Project Teams. 
Parag, Y. (2020). Which factors influence large households' decision to join a time-of-use program? The interplay between demand flexibility, personal benefits and national benefits. Renewable and Sustainable Energy Reviews, 110594.

Piccolo, L. S., De Liddo, A., Burel, G., Fernandez, M., \& Alani, H. (2018). Collective intelligence for promoting changes in behaviour: a case study on energy conservation. Al \& SOCIETY, 33(1), $15-25$.

Pillay, D. (2013). Electricity conservation: factors influencing sustainable energy efficient consumer behaviour in the South African household. Citeseer.

Prokopy, L. S., Floress, K., Arbuckle, J. G., Church, S. P., Eanes, F. R., Gao, Y., . . Singh, A. S. (2019). Adoption of agricultural conservation practices in the United States: Evidence from 35 years of quantitative literature. Journal of Soil and Water Conservation, 74(5), 520-534.

Rogge, K. S., Pfluger, B., \& Geels, F. W. (2020). Transformative policy mixes in socio-technical scenarios: The case of the low-carbon transition of the German electricity system (2010-2050). Technological Forecasting and Social Change, 151, 119259.

Saaty, T. L. (1994). How to make a decision: the analytic hierarchy process. Interfaces, 24(6), 19-43.

Shahmohammadi, M. S. (2015). DEVELOPMENT OF SYSTEM DYNAMIC MODEL TO EVALUATE THE IMPACT OF FEED-IN TARIFF FOR DIFFERENT ENERGY RESOURCES.

Shahzad, U., Doğan, B., Sinha, A., \& Fareed, Z. (2020). Does Export product diversification help to reduce energy demand: Exploring the contextual evidences from the newly industrialized countries. Energy, 214, 118881.

Shove, E. (2010). Beyond the ABC: climate change policy and theories of social change. Environment and planning $A, 42(6), 1273-1285$.

Skulmoski, G. J., Hartman, F. T., \& Krahn, J. (2007). The Delphi method for graduate research. Journal of Information Technology Education: Research, 6(1), 1-21.

Sorrell, S. (2015). Reducing energy demand: A review of issues, challenges and approaches. Renewable and Sustainable Energy Reviews, 47, 74-82.

Stern, P. C. (1992). What psychology knows about energy conservation. American Psychologist, 47(10), 1224.

Tozer, L., \& Klenk, N. (2018). Discourses of carbon neutrality and imaginaries of urban futures. Energy research \& social science, $35,174-181$.

Williams, S. P., Thondhlana, G., \& Kua, H. W. (2020). Electricity Use Behaviour in a High-Income Neighbourhood in Johannesburg, South Africa. Sustainability, 12(11), 4571. 